1 Secretaria de Estado da Saúde de São Paulo (SES/ SP), Instituto de Saúde (IS) - São Paulo (SP), Brasil. ligia.duarte@uol.com.br

2 Universidade de São Paulo (USP), Faculdade de Saúde Pública (FSP) - São Paulo (SP), Brasil.

\section{Tendências da mercantilização no SUS do estado de São Paulo: análise territorial dos gastos com convênios e contratos de gestão com Organizações Sociais}

\author{
Trends of commodification in the SUS of the state of São Paulo: \\ territorial analysis of spending on agreements and management \\ contracts with Social Organizations
}

Ligia Schiavon Duarte', Jair de Abreu Leme Junior², Julia Amorim Santos², Luiz Victor Felipe', Áquilas Nogueira Mendes²

DOI: $10.1590 / 0103-1104202012702$

RESUMO As literaturas nacional e internacional indicam o redimensionamento do setor privado dentro dos sistemas públicos de saúde, com sua ampliação e constituição de novos arranjos. O trabalho objetiva analisar a dinâmica territorial no processo de mercantilização explícita no território do estado de São Paulo, identificando a distribuição espacial de recursos para a gestão privada de instituições públicas e a contratação de instituições sem fins lucrativos para a oferta de serviços. Recorreu-se às informações orçamentárias da Secretaria de Estado da Saúde de São Paulo, no período de 2010 a 2017. A análise dos dados permitiu observar uma participação relevante de despesas com gestão privada de instituições públicas $(25,8 \%)$ e com contratação de instituições sem fins lucrativos para oferta de serviços (12,0\%) nos gastos em saúde do estado, e o aumento real dos gastos em ambas as despesas ao longo do período. A análise territorial demonstrou que a contratação de gestão privada é um fenômeno característico da principal metrópole paulista, enquanto nas demais regiões prevalecem as despesas com contratação de instituições sem fins lucrativos para a oferta de serviços. Observa-se, também, que o estado despende recursos financeiros principalmente para a contratação da gestão dos equipamentos hospitalares, seguido dos ambulatórios.

PALAVRAS-CHAVE Economia da saúde. Organização Social. Mercantilização. Política de saúde. Gestão em saúde.

\begin{abstract}
National and international literature indicates a resizing of the private sector within the public health systems, providing its expansion and the establishment of new arrangements. The study aims to analyze the territorial dynamics in the process of explicit commodification in the state of São Paulo, identifying the territorial distribution of resources for the private management of public institutions and the contracting of non-profit institutions for the provision of health services. Budgeting information from the São Paulo State Department of Health was adopted from 2010 to 2017. Data analysis made possible to notice that a significant portion of health expenses was allotted to private management of public institutions (25.8\%) and to the supply of service by the contracting of non-profit institutions (12.0\%). Both spending actually increased over the period. The territorial analysis revealed that the contracting of private management is typical of the capital of São Paulo, while prevail in the other regions the expenses with the contracting of non-profit institutions for the provision of services. The State allot financial resources mainly for contracting the management of hospital equipment, followed by outpatient clinics.
\end{abstract}

KEYWORDS Health economics. Social Organization. Commodification. Health policy. Health management. 


\section{Introdução}

A partir de 1988, foi instituído o Sistema Único de Saúde (SUS) o qual visa a consolidar as políticas de saúde como direito social básico universal1. É considerada uma das políticas públicas de saúde mais progressistas do mundo, a qual prevê atendimento a todo brasileiro ou qualquer pessoa que estiver no País, pautada em diretrizes de um cuidado integral, com participação social e articulação das ações por meio da regionalização e de redes de serviços.

Para isso, na Constituição Federal de 1988, ficou estabelecido que o Estado deve garantir uma rede de serviços própria, sem, no entanto, excluir a possibilidade de participação de entidades privadas, quando necessário. Nesse sentido, a partir do artigo 197, ficou explicitado que o Poder Público deve dispor sobre a regulamentação, fiscalização e o controle das ações e dos serviços de saúde de relevância pública, devendo sua execução ser feita diretamente ou através de terceiros e, também, por pessoa física ou jurídica de direito privado'. Estabeleceu-se, também, a existência de uma rede de serviços privados que não possuiria vínculos com o sistema público (denominada 'serviços suplementares', por meio da Lei ${ }^{\circ}$ 8.080/1990), prestando serviço à população mediante pagamento direto ou por instituições que intermedeiam a relação prestador-consumidor ${ }^{2}$. A articulação entre os setores públicos e privados se constitui de maneira endógena nas políticas públicas de saúde no Brasil, e parte da literatura indica haver, ao longo dos 30 anos de existência do SUS, uma intensificação do arranjo público-privado ${ }^{3,4}$.

A partir de 1995, no governo do presidente Fernando Henrique Cardoso, foi instituída a Reforma da Administração Pública ${ }^{5}$, atribuindo ênfase à necessidade de modernizar a administração pública enquanto reguladora das atividades econômicas, tornando-a eficiente sob os critérios do mercado. Pautava-se a importância de integração com a economia mundial, com ênfase à privatização do setor industrial, ainda que ressaltando a necessidade de certa mediação estatal em algumas áreas sociais, como educação, saúde e cultura. Esse processo estava harmonizado com a consolidação do ajuste fiscal e uma política macroeconômica de implementação do Plano Real de caráter restritivo (ex. corte de gastos públi$\cos )^{6}$. Nessa proposta, a reforma gerencial se propôs a modernizar a administração pública com a passagem do que eles denominavam uma forma burocrática-estatal para uma forma gerencial, de maneira a tornar a administração pública eficiente sob os critérios do mercado, com o Estado atuando enquanto regulador das atividades econômicas.

Para essa modernização, o aumento da eficiência da administração pública, segundo os propositores, seria resultado de um complexo projeto de reforma no setor dos serviços 'não exclusivos' do Estado. Reafirmou-se que o setor de bens e serviços deveria ser voltado totalmente para o mercado, e a produção deveria ser, em princípio, realizada pelo setor privado. Quanto às atividades que não pudessem ser controladas exclusivamente pelo mercado, o Estado deveria assumir um caráter regulador e transferidor de recursos à figura jurídica denominada 'pública não-estatal'?.

Essa não foi expressão singular brasileira. Observa-se um movimento internacional onde os sistemas de saúde passaram por reformas que introduziram, ainda que de maneira parcial, mecanismos de mercado ${ }^{8-10}$. Ferreira e Mendes 11 indicam a importância de compreender as dinâmicas de mudanças nos sistemas de saúde universais, considerando a especificidade de cada arranjo e dinâmica local, com a ampliação de formas já existentes e a criação de novos mecanismos de mercado.

No âmbito do Brasil, verifica-se a aprovação da Lei Federal no 9.637/1998, que implementou as Organizações Sociais como 'novos modelos de gestão não-estatal'12,13, concomitantemente à implementação das agências reguladoras autônomas - no caso da saúde, instituiu-se a Agência Nacional de Vigilância Sanitária, em 1999, e a Agência Nacional de Saúde Suplementar, em $2000^{14}$; além da aprovação 
da Lei de Responsabilidade Fiscal (oficialmente, Lei Complementar - LC - $\mathrm{n}^{\circ} 101$, de 2000), pautada pela agenda econômica do Fundo Monetário Internacional (FMI), que, entre outras coisas, estabeleceu limites para gastos com pessoal pelos entes federados ${ }^{15,16}$. É a partir desse conjunto de medidas instituídas ao longo da Reforma do Estado, imbricado no contexto de uma política macroeconômica ortodoxa com a instituição do tripé econômico (juros altos/metas de inflação, superávit primário e câmbio flutuante, com tendência a valorização do Real frente ao Dólar), que há a necessidade de reconfiguração das políticas sociais brasileiras nos anos $1990^{6,16}$.

O contexto dessa nova racionalidade dos gastos públicos afeta profundamente as políticas sociais, em especial, a de saúde. Ao longo da década de 1990, o processo de implantação do SUS, com a estratégia de descentralização nas suas principais diretrizes, por si só, já introduz mudanças importantes na organização da política. A municipalização da saúde, principalmente a partir de 1996, promove inúmeras inovações relacionadas à eficácia e eficiência da gestão do sistema, em diferentes perspectivas, estando entre elas o aparecimento de novos atores - gestores municipais, gestores estaduais, conselhos, entre outros - e uma transformação na relação entre público e privado no sistema de saúde. Se, por um lado, a política que conforma o SUS exige o fortalecimento do papel do Estado, por outro, a rearticulação interna da iniciativa privada no setor saúde se dá com ênfase na modernização tecnológica e em uma suposta eficiência e qualidade dos serviços, ganhando espaço político e legitimidade social ${ }^{17}$.

Segundo Bodstein e Souza ${ }^{17}$, o novo desenho institucional passa a comportar inúmeras modalidades de organização e gestão, conforme o arranjo político em cada contexto local, que possibilita ao capital privado na saúde uma diversificada frente de atuação. Sejam naquelas baseadas em uma relativa autonomia com relação ao financiamento público direto, já que, de forma indireta, beneficia-se das renúncias fiscais, ou na possibilidade de ter seus clientes privados atendidos nos equipamentos públicos de maior complexidade, sejam naquelas baseadas no financiamento público direto, entre elas, a manutenção de convênios com o setor público, em especial, com os estaduais e municipais, para a provisão de serviços de saúde.

É possível afirmar que a provisão dos serviços de saúde tornou-se um campo primordial para o desenvolvimento de uma frente de atuação do setor privado, mesmo quando se consideram os países tradicionalmente reconhecidos por seus sistemas de proteção social ${ }^{10}$. Segundo Pahim ${ }^{\mathbf{1 0}}$, ainda que se reconheçam as dificuldades em estabelecer com precisão as fronteiras entre o público e o privado nas perspectivas de rentabilidade do setor privado, a separação da função provisão e da função compra coloca os provedores em busca permanente de ampliar seus nichos de mercado, intentando preservar ou expandir suas receitas.

É nesse contexto que a Lei no 9.637/1998 promove a adoção do modelo das Organizações Sociais de Saúde (OSS). Se, por um lado, a adesão ao modelo OSS pelos gestores municipais e estaduais decorre da maior flexibilização administrativa frente às regras impostas ao ente público, possibilitando a contratação de pessoal nas condições de mercado, a adoção de normas próprias para compras e contratos e a ampla flexibilidade na execução orçamentária e financeira ${ }^{18}$, por outro, possibilita às entidades qualificadas como Organizações Sociais (OS) cumprirem o papel de locus de valorização do capital. Segundo Morais et al.18, a possibilidade de remuneração dos dirigentes com os recursos públicos, de aplicação dos excedentes monetários na dinâmica da financeirização dos capitais e o posicionamento dessas entidades entre as maiores empresas do País figurariam esse setor como um componente do Complexo Econômico Industrial da Saúde.

A despeito do intenso debate sobre os reais resultados da implementação de um modelo de organização pública não estatal destinado a absorver atividades publicizáveis ${ }^{\mathbf{1 0 , 1 8 , 1 9}}$, governos de diversos matizes ideológicos vêm adotando, 
em diferentes territórios e áreas de atuação, orientações gerais dos processos de reforma, dentro de uma dinâmica política que converge para o uso de instrumentos semelhantes para provisão de serviços públicos no contexto da Nova Gestão Pública. Governar de forma indireta aos instrumentos de gestão tem sido uma tendência mundial, e, no Brasil, essa adoção no nível estadual tem sido intensificada sobretudo no que concerne às políticas de saúde.

Segundo Alcântara ${ }^{20}$ e Leite ${ }^{21}$, as novas formas organizacionais do setor público, mais notadamente as OSS, devem passar por um processo contínuo e profundo de avaliação, e um desenho organizacional deverá ser sistematizado para que haja mecanismos de avaliação e controle efetivos. Os contratos de gestão têm sido apontados como deficientes em alguns aspectos, sendo que há necessidade de aprimorar as técnicas de mensuração da eficiência, controle e sobretudo os métodos de fiscalização externa. Os autores ressaltam que, até o momento, não há avaliações confiáveis que demonstrem maior eficiência dessas novas organizações. É comum na administração brasileira a existência de reformas com pouco planejamento e fundamentação, o que propicia resultados parciais e insatisfatórios, que buscam apenas escapar da alegada rigidez do ordenamento jurídico, especialmente do direito administrativo público. Para Mendonça e Machado 22, as práticas de Governança Corporativa são referenciadas nos princípios de transparência, equidade, prestação de contas e ética. Os autores afirmam que deve existir, nas organizações do terceiro setor, mecanismos de governança passíveis de implementação para que se alcance desempenho social eficiente.

A partir da opção pelas OSS para execução dos serviços no modelo de gestão, um dos principais questionamentos diz respeito à possibilidade de privatização das unidades estatais. E esse tem sido, também, apesar de uma tendência, um dos fatores de resistência explícita ao modelo, pelos atores políticos do SUS, nos espaços de decisão colegiada ${ }^{23}$.
O fato é que, no Brasil, a Lei nº 9.637/1998 promoveu uma notável concentração das OSS no eixo Sul-Sudeste do País, que se relaciona ao dinamismo econômico regional nacional ${ }^{18}$. A tendência de concentração regional do financiamento público do setor de saúde ${ }^{24,25}$ e dos prestadores privados de saúde, em especial, os filantrópicos ${ }^{10,26}$, em regiões de maior desenvolvimento econômico do País e em polos urbanos é fenômeno já identificado na literatura especializada.

Além de estarem concentradas territorialmente, Morais et al. ${ }^{18}$ ressaltam a capacidade das dez maiores OSS, localizadas em São Paulo e no Rio de Janeiro, de expandirem-se pelo território nacional, alcançando localidades, contíguas ou não, configurando um movimento que sugere a formação de monopólios. As autoras demonstram, ainda, ampliação do número de estabelecimentos públicos gerenciados por OSS com contrato de gestão, nas esferas estaduais e municipais, de 2009 a 2016. Vale ressaltar, ainda, que o perfil assistencial dos estabelecimentos sob gestão privada é, em sua grande maioria, de hospitais, principalmente os gerais ${ }^{18}$. Mesmo considerando que o perfil assistencial dos estabelecimentos sob gestão privada seja em grande parte hospitalar, é possível observar a expansão do modelo OSS para unidades ambulatoriais, de análises clínicas e centros de atendimento a grupos específicos ${ }^{10}$.

Pahim ${ }^{10}$, ao analisar a implementação das OSS no estado de São Paulo, identifica que, além da LC 846/98, que autoriza o governo estadual a qualificar como 'organizações sociais' entidades privadas sem fins lucrativos com atuação voltada às áreas de saúde e cultura, estabeleceu-se a LC 62/08, que determina uma ampliação no raio de abrangência desse formato de gestão. A autora constata que, durante o período de 1998-2007, a Pasta da Saúde foi privilegiada, sendo que o modelo OSS se desenvolveu num contexto especialmente favorável do ponto de vista de condições de financiamento. Verifica que houve uma tendência de aumento dos gastos com contratos de gestão ou convênios, havendo um expressivo 
ganho de espaço relativo ao modelo OSS no orçamento da Secretaria de Estado da Saúde de São Paulo (SES/SP) na década de 2000. Segundo a autora, a implementação do modelo OSS pela SES/SP se constituiu em três fases: 1) $1998-2001$, com a instituição da gerência de unidades hospitalares; 2) 2002-2004, com a introdução de novo formato de contrato de gestão e interiorização para alguns hospitais no território paulista; 3) 2005-2008, com a incorporação de outros tipos de serviços de saúde ao rol de contratos e convênios com as entidades gerenciadoras.

Como indicado, esse processo de redimensionamento do setor público e do setor privado, com a constituição de novos arranjos institucionais, pode ser observado em âmbito internacional. A literatura apresenta os termos de mercantilização, privatização e comercialização para indicar essa expressão do aumento da lógica privada dentro dos sistemas públicos de saúde, seja considerando o aumento da participação direta do setor privado enquanto prestador de serviços e de recursos privados no financiamento, assim como a adoção de princípios privados de gestão, remuneração e organização dos sistemas 27,28 .

Ferreira e Mendes11, analisando a inserção de mecanismos de mercado nas reformas dos sistemas de saúde da Alemanha, França e Reino Unido, adotam o termo 'mercantilização' para caracterizar o processo e identificam nele quatro tendências combinadas em termos de processos explícitos e implícitos, que podem se dar tanto pelo financiamento quanto pela oferta de serviços. No presente estudo, adotar-se-á como referência a tendência identificada como 'mercantilização explícita na oferta de serviços', que compreende a transferência de responsabilidade do setor público para o setor privado na oferta de serviços, em específico, na sua incorporação na oferta de serviços e na gestão privada de instituições públicas.

Partindo do exposto, este trabalho propôs-se a analisar a dinâmica territorial no processo de mercantilização explícita no estado de São Paulo. A meta foi verificar a distribuição espacial de recursos para a gestão privada de instituições públicas e a contratação de instituições sem fins lucrativos para a oferta de serviços no âmbito dessa esfera de governo, partindo da análise da alocação de recursos da SES/SP, a fim de jogar luz sobre a disseminação do modelo OSS no território paulista.

\section{Material e métodos}

Trata-se de estudo descritivo e exploratório, de natureza quantitativa e de corte longitudinal retrospectivo. As informações que compuseram a análise realizada foram coletadas no Sistema de Informações e Execução Orçamentária (Sigeo), referentes aos gastos em saúde da SES/SP. Entende-se que quanto maior a série histórica melhor a compreensão da tendência dos gastos, porém, a análise compreendeu o período de 2010, primeiro ano disponível no Sigeo, a 2017, último ano fechado no momento da realização do estudo.

Foram selecionados na base do Sigeo apenas os gastos classificados na função 10 Saúde. O conceito de gasto em saúde é o proposto por Mendes, Marques, Leite e Tubone ${ }^{29}$ e compreende toda despesa com serviços de saúde de acesso universal, envolvendo as atividades desenvolvidas pela SES/SP (administração direta) e as transferências realizadas às entidades descentralizadas - Fundações e Autarquias - (indireta). Optou-se, também, por considerar apenas os gastos realizados com os recursos oriundos das arrecadações recebidas pelo governo estadual, ou seja, do Tesouro Estadual, por se aproximarem dos gastos vinculados ao percentual obrigatório da receita própria para aplicação em saúde definido pela Emenda Constitucional 29 (EC 29) ${ }^{30}$. São gastos definidos no âmbito da gestão estadual, sem interferência direta da política do governo federal.

Para compreender a dinâmica relacionada ao processo de mercantilização explícita na oferta de serviços, foram destacadas algumas despesas na base de dados. As despesas referentes à contratação de gestão privada na 
oferta de serviços, ou seja, contratação das OSS para gerenciamento de equipamentos estaduais, identificadas como Contratos de Gestão - LC 846/98 (no item 3.3.90.39). No presente estudo, essas despesas foram denominadas 'Contratos de Gestão com OSS'. Ainda, para identificar a incorporação do setor privado na oferta de serviços, foram destacadas as despesas classificadas na modalidade de aplicação 50, que se referem às 'Transferências a Instituições Privadas sem Fins Lucrativos', cujos itens de despesas foram definidos da seguinte forma: i) Item 3.3.50.43.79 - 'Convênios com Organizações Sociais'; ii) Item 3.3.50.43.74 - 'Convênios com faculdades sem fins lucrativos'; iii) Item 3.3.50.43.76 - 'Convênios com as Santas Casas'; e iv) Itens 3.3.50.43.72, 3.3.50.43.75, 3.3.50.43.90 - 'Outros convênios'. A somatória das despesas classificadas nesses itens foi denominada 'Convênios'.

Consideraram-se, para efeito da análise do gasto, as 'Despesas liquidadas', o que indica que os valores não incluem os chamados 'Restos a pagar' daquele mesmo ano, considerando, assim, apenas as despesas processadas onde o direito do credor já foi verificado. Os valores foram tabulados e deflacionados utilizando o Índice Geral de Preços - Disponibilidade Interna (IGP/DI - Fundação Getúlio Vargas - base = janeiro de 1993) - e convertidos a preço com base no índice de dezembro/2017, permitindo a comparação na série histórica em valor real.

O Sigeo possibilita acessar as informações das despesas liquidadas por município no qual ocorreu o gasto. Tendo em vista a compreensão da dinâmica territorial da realização das despesas, a base de dados foi retirada por municípios, que posteriormente foram codificados por regiões de saúde, conforme deliberação da Comissão Intergestores Bipartite (CIB) $n^{0}$ 153 , de 2007, e posteriormente alterada pela CIB $n^{\circ} 4$, de $2012^{31,32}$. Vale ressaltar a presença residual na base de dados do Sigeo de municípios pertencentes a outros estados da federação, os quais foram classificados como Outros Estados.
Com o intuito de promover a análise da dinâmica territorial dos gastos e diante da importância da Região Metropolitana de São Paulo (RMSP) como locus privilegiado das despesas realizadas com a contratação de instituições sem fins lucrativos, optou-se no presente estudo por classificar as seis regiões de saúde localizadas na RMSP (Alto do Tietê, Franco da Rocha, Grande ABC, Mananciais, Rota dos Bandeirantes e São Paulo) como 'Regiões de Saúde da Região Metropolitana de São Paulo', e as demais 57 regiões de saúde paulistas como 'Demais Regiões'. Ou seja, as 63 regiões de saúde paulistas foram classificadas em dois grupos: as pertencentes à RMSP, denominadas 'Regiões de Saúde da RMSP', e as não pertencentes à RMSP, denominadas 'Demais Regiões'.

As informações disponíveis no Sigeo não permitem identificar o nível assistencial das unidades sob a gestão das OSS. Por esse motivo, recorreu-se ao Portal Financeiro do Gestor da Coordenadoria de Gestão Orçamentária e Financeira da Secretaria de Estado da Saúde de São Paulo (CGOF - SES/SP) como forma de complementar a análise da dinâmica territorial. Por meio desse portal, a SES disponibiliza consultas detalhadas por tipo, objeto, fonte de financiamento, entre outros, de todos os repasses realizados por ela. Foi possível construir uma base de dados com os repasses para OSS e contratos de gestão consolidados segundo a gestora e a unidade contratualizada, no ano de 2017. A referida base de dados foi complementada com o município da sede da OSS e com o município no qual se encontra a unidade contratualizada, e, em seguida, os municípios foram classificados como pertencentes à RMSP ou como Demais Regiões. Finalmente, as unidades contratualizadas foram classificadas da seguinte forma: i) hospitais; ii) Ambulatório Médico de Especialidades (AME); e iii) demais unidades. A título de exemplo, neste último se encontram os Serviços Estaduais de Diagnóstico por Imagem (Sedi), a Rede Lucy Montoro, a Central de Regulação de Oferta de Serviços de Saúde (Cross), entre outros. 
Após as classificações propostas serem inseridas na base de dados, foram identificadas três unidades contratualizadas sob a gestão de duas OSS diferentes. Nesses três casos, os contratos de gestão das unidades contratualizadas foram consultados no Portal da Transparência da SES/SP. Os registros das OSS cujos contratos não foram identificados foram retirados da base de dados. Após esse processo de crítica das informações, o valor total dos repasses para as OSS, que somava R \$ 4.857,20 milhões em 2017, passou para R \$ 4.838,00 milhões. Vale ressaltar que os valores de repasses registrados no Portal Financeiro do Gestor são definidos no âmbito da CGOF - SES/SP (dados financeiros), não devendo ser comparados aos valores encontrados do Sigeo (dados orçamentários), servindo exclusivamente como parâmetro para a análise da dinâmica da contratação de gestão privada de instituições públicas pela SES/SP.

\section{Resultados e discussões}

Conforme pode ser observado na tabela 1, considerando o período de 2010 a 2017, a SES despendeu $\mathrm{R} \$ 124,72$ bilhões do tesouro estadual, sendo que $\mathrm{R} \$ 15,02$ bilhões foram transferências a Instituições Privadas sem Fins Lucrativos para a compra de serviços por meio de 'Convênios', e R \$ 32,2 bilhões em 'Contratos de Gestão com OSS', que representam $12,0 \%$ e $25,8 \%$ do total dos gastos, respectivamente. Vale ressaltar que, em 2017, último ano do período analisado, os Contratos de Gestão com OSS representaram $28,5 \%$ do total de gastos, enquanto, em 2010, esse valor correspondia a $23,7 \%$.

Tabela 1. Gastos estaduais por tipos de despesas e ano, no estado de São Paulo, período de 2010 a 2017

\begin{tabular}{lccccr}
\hline & \multicolumn{2}{c}{ Convênios } & \multicolumn{2}{c}{ Contratos de Gestão OSS } & Total \\
Ano & Abs. & Part. & Abs. & Part. & Abs. \\
\hline 2010 & $1.602,42$ & $11,5 \%$ & $3.301,77$ & $23,7 \%$ & $13.949,29$ \\
2011 & $1.757,49$ & $12,3 \%$ & $3.565,84$ & $24,9 \%$ & $14.333,42$ \\
2012 & $1.666,99$ & $11,2 \%$ & $3.972,20$ & $26,8 \%$ & $14.842,85$ \\
2013 & $1.774,74$ & $10,6 \%$ & $4.478,29$ & $26,7 \%$ & $16.776,91$ \\
2014 & $2.156,78$ & $13,1 \%$ & $3.972,72$ & $24,1 \%$ & $16.496,11$ \\
2015 & $1.964,12$ & $12,2 \%$ & $4.091,34$ & $25,3 \%$ & $16.144,88$ \\
2016 & $2.265,12$ & $14,4 \%$ & $4.122,03$ & $26,3 \%$ & $15.681,09$ \\
2017 & $1.836,21$ & $11,1 \%$ & $4.701,86$ & $28,5 \%$ & $16.500,35$ \\
\hline Total & $\mathbf{1 5 . 0 2 3 , 8 7}$ & $\mathbf{1 2 , 0} \%$ & $\mathbf{3 2 . 2 0 6 , 0 5}$ & $\mathbf{2 5 , 8} \%$ & $\mathbf{1 2 4 . 7 2 4 , 8 9}$ \\
\hline
\end{tabular}

Fonte: Sigeo ${ }^{33}$

Nota: Em reais, dez/2017. Deflator IGP-DI-FGV.

De fato, analisando o comportamento da despesa com 'Contratos de Gestão com OSS' e com 'Convênios' ao longo do período analisado, observa-se que ambas apresentam crescimento real, sendo que a primeira apresentou maior aumento quando comparada com a segunda, conforme pode ser observado na linha de tendência no gráfíco 1. Essa constatação permite depreender que a ampliação das despesas com o modelo OSS no orçamento estadual, identificado por Pahim ${ }^{10}$ em meados da década de 2000 , tem continuidade ao longo da década de 2010.

A análise desagregada das despesas com 'Convênios' permite observar que os 'Convênios com Organizações Sociais', que respondem pela maior parcela dentro do agregado no início do período, perdem participação ao longo do tempo, passando a representar a 
menor parcela em 2017. As demais despesas com Convênios apresentam aumento real ao longo do período, com destaque para as despesas com 'Outros convênios' e, em menor intensidade, com 'Convênios com as Santas Casas’ (gráfico 1).

Gráfico 1. Gastos estaduais por tipos de despesas e ano, no estado de São Paulo, período de 2010 a 2017
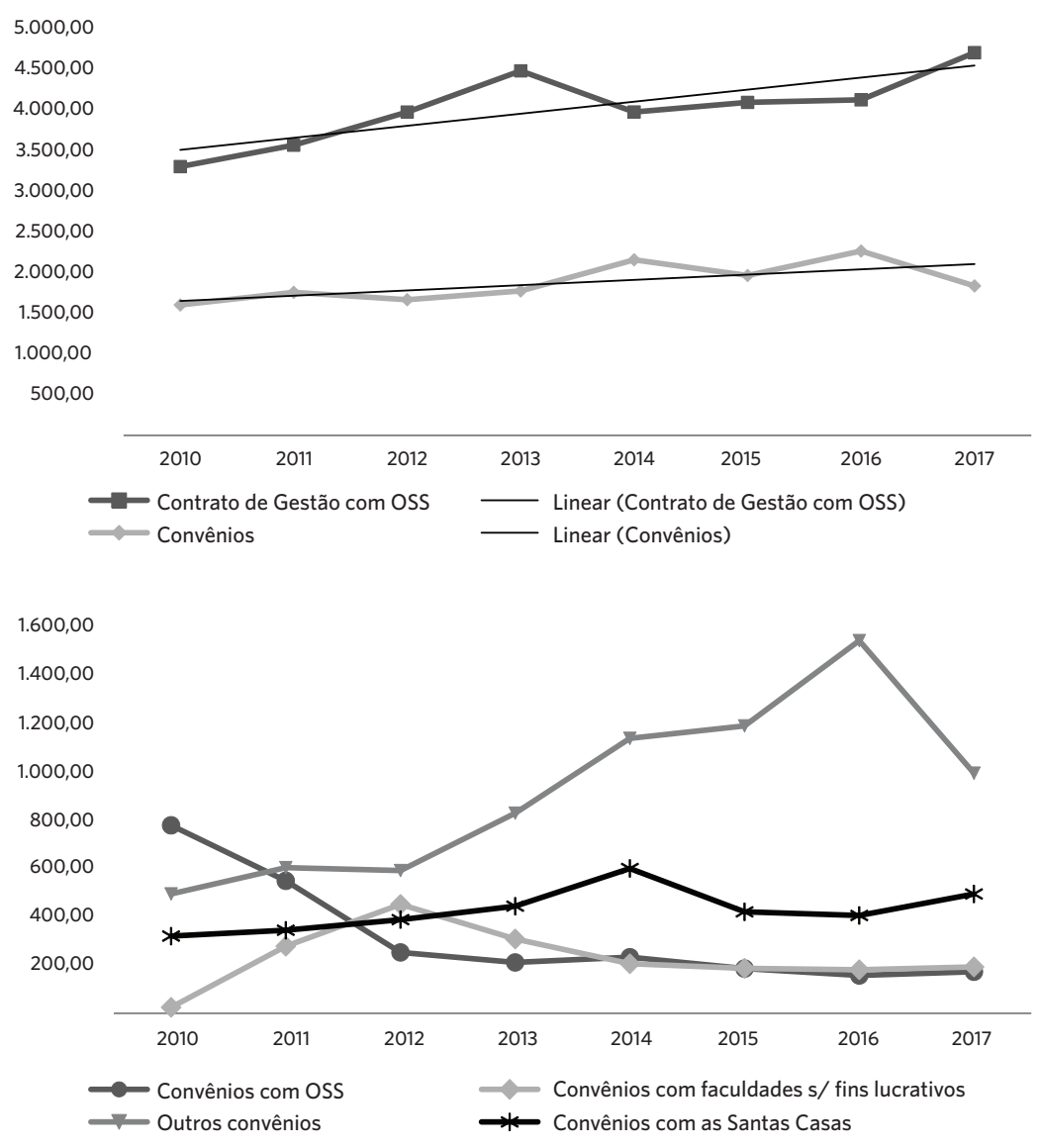

Fonte: Sigeo ${ }^{33}$

Nota: Em reais, dez/2017. Deflator IGP-DI-FGV.

A análise da alocação de recursos pela SES/SP indica que, ao longo do período 2010 a 2017, ocorreu uma ampliação do processo de mercantilização explícita na oferta de serviços. Observou-se o crescimento real das despesas com convênios, o que representa a incorporação do setor privado na oferta de serviços, apesar dessa despesa ser inferior ao crescimento da gestão privada de instituições públicas, analisada por meio dos Contratos de Gestão com OSS. Esses achados demonstram consonância com a ampliação do processo de mercantilização na oferta de serviços verificada nos países centrais, mais especificamente, na Inglaterra, na França e na Alemanha ${ }^{11,34}$.

Pelo montante de recursos despendidos no período analisado, que representa mais do que o dobro das despesas com convênios, vale destacar que as despesas com a contratação de gestores privados para as instituições públicas caracterizam de forma determinante a mercantilização explícita da oferta de serviços no estado de São Paulo. Sugere, também, a preeminência do modelo OSS como nicho de 
mercado para manter ou expandir a lucratividade do setor privado, quando comparado ao setor de provisão de serviços de saúde.

A análise da distribuição territorial das despesas com 'Contratos de Gestão com OSS' ao longo do período analisado permitiu verificar que cerca de 78,6\% delas se concentram na RMSP. Já com relação às despesas com 'Convênios', a situação se inverte, com 59,2\% realizadas nas demais regiões. Esse resultado deve-se à forte presença dos 'Convênios com Organizações Sociais', dos 'Convênios com faculdades sem fins lucrativos' e dos 'Convênios com as Santas Casas' nas demais regiões, que se concentram em $72,6 \%, 96,4 \%$ e $72,4 \%$, respectivamente, nas regiões de saúde desse recorte territorial. Apenas os convênios classificados como 'Outros convênios' apresentam maior concentração nas regiões de saúde que compõem a RMSP (tabela 2). Pode-se fazer a ponderação, também, da correlação encontrada na literatura de haver concentração tanto no âmbito territorial como concentração em instituições e ampliação da formação de monopólios ${ }^{\mathbf{1 8}}$.

Vale ressaltar que as despesas realizadas com 'Convênios com as Santas Casas' são bastante distribuídas pelo território, sendo direcionadas para 60 das 63 regiões de saúde do estado de São Paulo. Já os 'Convênios com Organizações Sociais' atingem 12 regiões de saúde, enquanto os 'Convênios com faculdades sem fins lucrativos' são direcionados para apenas seis regiões de saúde, sendo elas: Aquífero Guaraní, Marília, Polo Cuesta, São Paulo, Vale do Paraíba/Região Serrana e Região Metropolitana de Campinas. Destaque para esta última que recebe cerca de $66 \%$ do total das despesas com 'Convênios com faculdades sem fins lucrativos'. Tais dados evidenciam a importância das instituições de ensino de medicina, sobretudo públicas, localizadas nos maiores polos regionais do estado, confirmando, assim, a tendência para a concentração dos repasses de recursos públicos de forma seletiva no território, conforme aponta Duarte ${ }^{24}$.

Tabela 2. Gastos estaduais por região selecionada e tipos de despesas, no estado de São Paulo, período de 2010 a 2017

\begin{tabular}{lrrrrrr}
\hline & \multicolumn{2}{c}{ Demais regiões } & \multicolumn{2}{c}{ RMSP } & \multicolumn{2}{c}{ Total Geral } \\
Despesas & Abs. & $\%$ & Abs. & $\%$ & Abs. & $\%$ \\
\hline Contratos de Gestão com OSS & $6.889,37$ & 21,4 & $25.316,68$ & 78,6 & $32.206,05$ & 100,0 \\
Tota I - Convênios & $8.891,68$ & 59,2 & $6.132,19$ & 40,8 & $15.023,87$ & 100,0 \\
Convênios com OSS & $1.824,99$ & 72,6 & 687,41 & 27,4 & $2.512,40$ & 100,0 \\
Convênios com faculdades sem fins lucrativos & $1.742,26$ & 96,4 & 65,02 & 3,6 & $1.807,28$ & 100,0 \\
Convênios com as Santas Casas & $2.448,01$ & 72,4 & 935,39 & 27,6 & $3.383,40$ & 100,0 \\
Outros convênios & $2.876,43$ & 39,3 & $4.444,36$ & 60,7 & $7.320,79$ & 100,0 \\
\hline
\end{tabular}

Fonte: Sigeo 33

Nota: Em reais, dez/2017. Deflator IGP-DI-FGV.

Ainda que as despesas com 'Contratos de Gestão com OSS' estejam fortemente concentradas na RMSP, é digno de nota o aumento de participação dessas despesas nas demais regiões ao longo do período analisado. O gráfico 2 permite observar a maior tendência de crescimento das despesas com
'Contratos de Gestão com OSS' nas demais regiões, quando comparada à tendência de crescimento da RMSP. De fato, enquanto a taxa de crescimento dessas despesas na RMSP no período de 2010 a 2017 é de $2,7 \%$ ao ano, nas demais regiões é de $12,7 \%$ ao ano. 
Gráfico 2. Gastos estaduais por tipos de despesas segundo regiões selecionadas e ano, no estado de São Paulo, período de 2010 a 2017

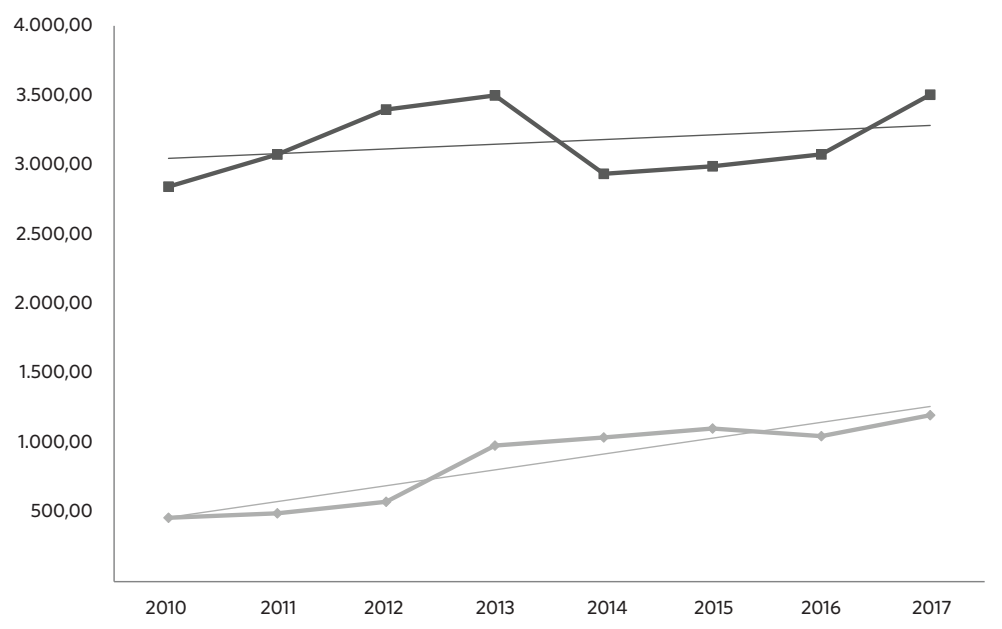

Fonte: Sigeo ${ }^{33}$

Nota: Em reais, dez/2017. Deflator IGP-DI-FGV.

Com relação às despesas com convênio, além do aumento real dos valores ao longo do tempo, foi possível observar uma mudança no perfil das instituições sem fins lucrativos contratadas. Enquanto, no início do período, os convênios eram realizados principalmente com OS, no final do período, ganham destaque as instituições classificadas como 'Outros convênios' e as 'Santas Casas'. Por outro lado, ao mesmo tempo que as OS perdem relevância nas despesas com convênio, as OSS ampliam sua participação na execução orçamentária do estado por meio das despesas com contratos de gestão de instituições públicas.

Quanto à distribuição espacial das despesas analisadas, considerando o recorte territorial proposto, observa-se a forte concentração nas regiões de saúde que compõem a RMSP, resultado da grande concentração de importantes instituições privadas e públicas de saúde nesta região. É possível observar que a contratação de gestores privados para a gestão das instituições públicas caracteriza mais fortemente a mercantilização explícita da oferta de serviços da RMSP. As demais regiões têm maior participação relativa nas despesas com convênios, ou seja, na contratação do setor privado como ofertante de serviços. No entanto, vale ressaltar que a maior tendência observada de crescimento das despesas com 'Contratos de Gestão com OSS' nas demais regiões pode indicar que está em curso um processo de espraiamento da lógica de contratação de gestão privada de instituições públicas rumo ao interior, conforme apontado em estudo realizado por Morais et al. ${ }^{\mathbf{1 8}}$.

Segundo informações disponíveis no Portal Financeiro do Gestor para o ano de 2017, é possível identificar 29 instituições qualificadas como OSS e contratadas pelo governo do estado de São Paulo para realizar a gestão de 111 unidades de saúde estaduais espalhadas no território paulista. Das 29 OSS, 12 têm sede na RMSP, sendo 10 no município de São Paulo, uma no município de Santo André e uma no município de Cotia. As 17 instituições restantes têm sede em 17 diferentes municípios localizados fora da RMSP.

Com relação às 111 unidades de saúde sob gestão das OSS, a maior parte é composta por AME (57), seguidos por hospitais (31) e demais unidades (23), conforme pode ser verificado 
na tabela 3. No entanto, ao se considerarem os valores repassados, verifica-se a preponderância do hospital no direcionamento dos recursos, cujos contratos responderam por $\mathrm{R} \$$ 3.366,60 milhões, sendo $\mathrm{R} \$$ 830,20 milhões para a contratação de gestão de AME e R \$ 641,20 milhões direcionados para as demais unidades de saúde.

Assim, mesmo que o direcionamento de recursos públicos para a contratação de gestão privada para estabelecimentos hospitalares se mantenha conforme identificado por diferentes autores ${ }^{10,18,35}$, observa-se a diversificação do perfil assistencial de estabelecimentos que vêm sendo submetidos ao modelo OSS.

Sobre a distribuição territorial, observa-se que dos R $\$ 4,84$ bilhões repassados em 2017 , $72,6 \%$ são empregados na gestão de equipamentos localizados na RMSP. Tal fato se baseia, sobretudo, na contratação de gestão privada para os hospitais públicos, bastante concentrados na RMSP (75,0\%). Os recursos repassados para a contratação dos outros serviços de saúde também estão fortemente concentrados na RMSP (89,8\%), cabendo ressaltar que isso resulta, em parte, da presença de estabelecimentos cujas atividades são estratégicas, conforme apontado por Morais et al. ${ }^{18}$, como a Central de Regulação de Oferta de Serviços de Saúde (Cross) e do Centro Estadual de Armazenamento e Distribuição de Insumos de Saúde (Ceadis), no município de São Paulo. Já os recursos para a contratualização dos AME estão mais distribuídos espacialmente (tabela 3), sugerindo que a expansão territorial do modelo OSS observada também venha acompanhada da diversificação do perfil assistencial do estabelecimento sob gestão privada.

Tabela 3. Unidades de saúde e valores repassados por região selecionada e tipo de serviços, no estado de São Paulo, 2017

\begin{tabular}{lrrrrrrrrr}
\hline & \multicolumn{3}{c}{ Demais Regiões } & \multicolumn{3}{c}{ RMSP } & \multicolumn{3}{c}{ Total } \\
Serviços & $\mathbf{N}$ & Valor & $\%$ & N & Valor & $\%$ & N & Valor & $\%$ \\
\hline Total & 72 & $1.324,90$ & $27,4 \%$ & 39 & $3.513,10$ & $72,6 \%$ & 111 & $4.838,00$ & $100,0 \%$ \\
Hospital & 19 & 840,20 & $25,0 \%$ & 12 & $2.526,40$ & $75,0 \%$ & 31 & $3.366,60$ & $100,0 \%$ \\
AME & 43 & 419,40 & $50,5 \%$ & 14 & 410,80 & $49,5 \%$ & 57 & 830,20 & $100,0 \%$ \\
Outros & 10 & 65,30 & $10,2 \%$ & 13 & 575,90 & $89,8 \%$ & 23 & 641,20 & $100,0 \%$ \\
\hline
\end{tabular}

Fonte: Portal Financeiro do Gestor $\mathbf{3 6}$

As informações de 2017 retiradas do Portal Financeiro do Gestor permitem identificar os hospitais públicos localizados na RMSP como os principais serviços de saúde sob gestão privada quando se considera o volume de recursos repassados. No entanto, considerando a forte presença dos AME nas regiões de saúde fora da RMSP, junto com a tendência de crescimento das despesas com contratos de gestão nessas regiões, conforme visto, pode-se inferir que esteja ocorrendo fenômeno similar ao identificado na Alemanha e na Inglaterra. Segundo Ferreira e Mendes"1 , se no início da década de 2000 são os hospitais públicos que passam para a gestão privada, já em meados da década os governos criam novos mecanismos para possibilitar a mudança de gestão também no setor ambulatorial.

\section{Considerações finais}

O estudo em tela possibilita qualificar o processo de mercantilização empreendido pelo governo do estado de São Paulo ao longo do período 2010 a 2017, identificando como sua principal característica a contratação de gestão privada para a oferta de serviços. Observase que tanto as despesas com 'Contratos de Gestão com OSS' como as com 'Convênios' 
apresentam crescimento real, sendo que a primeira apresentou maior aumento quando comparada com a segunda, como explicitado. $O$ gasto efetivado com ambas as despesas, no período analisado, correspondeu a $37,8 \%$ do orçamento, confirmando a existência de um intenso e crescente imbricamento entre empresas privadas e financiamento público na organização do sistema de saúde do estado de São Paulo, já amplamente identificado na literatura ${ }^{10,18,19,35}$.

A análise territorial demonstrou que a contratação de gestão privada é um fenômeno característico da principal metrópole paulista, enquanto nas demais regiões prevalecem as despesas com contratação de instituições sem fins lucrativos para a oferta de serviços. No entanto, o estudo evidenciou o maior crescimento relativo das despesas com contratação de OSS para a gestão de serviços de saúde nas regiões não pertencentes à RMSP, indicando uma tendência de expansão territorial do modelo OSS, conforme apontada por Morais et al. ${ }^{18}$, que pode estar se concentrando nos principais polos econômicos regionais do estado afastados da metrópole paulista ${ }^{24}$.

A análise das informações sugere que a expansão territorial identificada está acompanhada da diversificação no perfil assistencial da unidade de saúde sob gestão privada, sobretudo dos AME, confirmando a tendência de maior desconcentração espacial de atividades de menor complexidade ${ }^{26}$. Cabe aqui, também, apontar que a interiorização da gestão privada dos AME pode significar uma estratégia de adequação territorial para manutenção, ou expansão, da rentabilidade das empresas privadas do setor saúde. Em outras palavras, tendo em conta a necessidade do setor privado de expandir seus espaços de valorização e que essa necessidade, no Brasil, passa pela estruturação de esquemas de subsídios cruzados $^{10}$, a transferência do modelo OSS para centros urbanos menores e para serviços de menor complexidade é mister. Nessa perspectiva, seria esperado que essa tendência de expansão do modelo OSS se aprofundasse, sobretudo para os principais polos econômicos do estado, conforme indicado por Duarte ${ }^{24}$, mesmo que a eficiência desses arranjos não se comprovasse.

Este estudo reforça a afirmativa, encontrada na literatura, de uma intensificação do arranjo público-privado nas políticas de saúde no Brasil. Como indicado anteriormente, a articulação entre os setores públicos e privados se constitui de maneira endógena nas políticas públicas de saúde no Brasil, mantida e reforçada tanto na Constituição de 1988 como na Reforma da Administração Pública, de 1995. Esse processo de redimensionamento do setor público e do setor privado, com a constituição de novos arranjos institucionais, pode ser observado, também, em âmbito internacional.

Embora não fosse de escopo deste estudo, pontua-se a necessidade de se desenvolverem outras pesquisas aprofundando a análise desse redimensionamento público-privado e sua dinâmica, como também que seja avaliado o impacto dessa articulação na rede de assistência e no cuidado à saúde. A partir de estudos desse processo de mercantilização das políticas públicas de saúde em países europeus, autores indicam riscos de seleção de pacientes, com possível inequidade de acesso e prejuízos à universalização do sistema ${ }^{8,11,28}$.

\section{Colaboradores}

Duarte LS (0000-0001-5822-9033)*, Leme Junior JA (0000-0003-3882-0963)*, Santos JA (0000-0002-4403-2165)*, contribuíram para a concepção, planejamento, análise e interpretação dos dados, elaboração do rascunho, revisão crítica do conteúdo e aprovação da versão final do manuscrito. Felipe LV (0000-0003-4871-8145)*, contribuiu para a análise e interpretação dos dados e elaboração do rascunho. Mendes AN (0000-0002-56324333)* contribuiu para a aprovação final do manuscrito.
*Orcid (Open Researcher and Contributor ID). 


\section{Referências}

1. Brasil. Constituição (1988). Constituição da República Federativa do Brasil. Brasília, DF: Senado Federal; 1988.

2. Brasil. Lei no 8.080, de 19 de setembro de 1990. Dispõe sobre as condições para a promoção, proteção e recuperação da saúde, a organização e o funcionamento dos serviços correspondentes e dá outras providências. Diário Oficial da União. 19 Set 1990.

3. Santos IS. Evidência sobre o mix público-privado em países com cobertura duplicada: agravamento das iniquidades e da segmentação em sistemas nacionais de saúde. Ciênc. Saúde Colet. 2011; 16(6):2743-2752.

4. Santos JAA. Ampliação do Processo de Privatização da Saúde Pública no Brasil. São Paulo: Hucitec; 2018.

5. Behring ER, Boschetti I. Política Social: fundamentos e história. 8. ed. São Paulo: Cortez; 2011.

6. Modenesi AM. Regimes Monetários: teorias e a experiência do real. Barueri: Manoli; 2015.

7. Bresser Pereira LC. A Reforma do Estado nos anos 1990: lógica e mecanismos de controle. Lua Nova: Rev. de Cul e Pol. 1998; (45):49-95.

8. Jonathan F, Giovanella L, Konder M, et al. A "liberalização" do Serviço Nacional de Saúde da Inglaterra: trajetória e riscos para o direito à saúde. Cad. Saúde Pública. 2016; 32(8):e00034716.

9. Macedo ME, Alves AM. Reforma administrativa: o caso do Reino Unido. Rev. Serv. Púb. 2014; 48(3):62-83.

10. Pahim MLL. Organizações Sociais de Saúde do Estado de São Paulo: Inserção Privada no SUS e Gestão Financeira do Modelo pela Secretaria de Estado da Saúde. [tese]. São Paulo: Universidade de São Paulo; 2009.

11. Ferreira MRJ, Mendes NA. Mercantilização nas reformas dos sistemas de saúde alemão, francês e britânico. Ciênc. Saúde Colet. 2018; 23(7):2159-2150.
12. Andreazzi MFS. Teias e trama: relações público privadas no setor saúde. [tese]. Rio de Janeiro: Instituto de Medicina Social; 2002.

13. Correia MV, Santos VM. Privatização da saúde via novos modelos de gestão: as Organizações Sociais em questão. In: Bravo MIS, Andreazzi MFS, Menezes JSB, et al., organizadoras. A mercantilização da saúde em debate: as organizações sociais no Rio de Janeiro. Rio de Janeiro: Universidade do Estado do Rio de Janeiro; Rede Sirius; 2015. p. 33-9.

14. Pó MV. Institucionalidade e desafios da regulação na área da saúde no Brasil. In: Santos NR, Amarante PDC. Gestão pública e relação público-privado na saúde. Rio de Janeiro: CEBES; 2011. p. 243-266.

15. Brasil. Lei Complementar $\mathrm{n}^{\circ} 101$, de 4 de maio de 2000. Estabelece normas de finanças públicas voltadas para a responsabilidade na gestão fiscal e dá outras providências. Diário Oficial da União. 5 Maio 2000.

16. Behring ER. Trabalho e Seguridade Social: o neoconservadorismo nas políticas sociais. São Paulo: Corte; 2008.

17. Bodstein R, Souza RG. Relação público e privado no setor saúde: tendências e perspectivas na década de 90. In: Goldenberg P, Marsiglia RMG, Gomes MHA. O clássico e o novo: tendências, objetos e abordagens em ciências sociais e saúde. Rio de Janeiro: Fiocruz; 2003. p. 289-309.

18. Morais HMM, Albuquerque MSV, Oliveira RS, et al. Organizações Sociais da Saúde: uma expressão fenomênica da privatização da saúde no Brasil. Cad. Saúde Pública. 2018; 34(1):e00194916.

19. Donadone JC, Baggenstoss S. Intermediários e as novas configurações no tecido organizacional brasileiro: Um estudo sobre as organizações sociais de saúde. Temp. Soc. 2017; 29(1):130-149.

20. Alcântara CM. Serviços sociais autônomos e a administração pública brasileira. Revista de Direito Adm. Const., 2009; 37(9):175-197. 
21. Leite AMGN. Organizações sociais de saúde e controle externo: uma análise a partir do Tribunal de Contas de Pernambuco [dissertação]. Recife: Fundação Oswaldo Cruz, Centro de Pesquisas Aggeu Magalhães; 2014.

22. Mendonça LR, Machado Filho CAP. Governança nas organizações do terceiro setor: considerações teóricas. Revista de Adm. 2004; 39(4):302-308.

23. Pacheco HF, Gurgel Júnior GD, Santos FAS, et al. Las organizaciones sociales como modelo de gestión de la asistencia sanitaria en Pernambuco, Brasil: percepciones de los gestores. Interface (Botucatu). 2016; 20(58):585-95.

24. Duarte LS. Desenvolvimento desigual e a regionalização do SUS: uma análise territorial dos recursos financeiros para as redes de atenção à saúde no Estado de São Paulo (2009-2014) [tese]. São Paulo: Universidade de São Pau$10 ; 2016$.

25. Duarte LS, Mendes AN, Louvison MCP. O processo de regionalização do SUS e a autonomia municipal no uso dos recursos financeiros: uma análise do estado de São Paulo (2009-2014). Saúde debate. 2018; 42(116):25-37.

26. Lima LD, Albuquerque MV, Scatena JHG, et al. Arranjos regionais de governança do Sistema Único de Saúde: diversidade de prestadores e desigualdade espacial na provisão de serviços. Cad. Saúde Pública. 2019; 35(supl2):e00094618.

27. Thomson CR, Mckee M. Financing and planning of public and private not-for-profit hospitals in the European Union. Health Policy. 2004; 67(3):281-291.

28. Maarse H. The Privatization of Health Care in Europe: Na Eight-Country Analysis. J. Health Politic. Polic. Law. 2006; 31(5):1014-982.

29. Mendes AN, Marques RM, Leite MG, et al. Financiamento da saúde: análise dos gastos estaduais e municipais do Estado de São Paulo. Brasília, DF: Ipea; 1999. (Projeto BRA 97/03).

30. Brasil. Emenda Constitucional $n^{\circ} 29$, de 13 de setembro de 2000. Altera os arts. 34, 35, 156, 160, 167 e 198 da Constituição Federal e acrescenta artigo ao Ato das Dis- posições Constitucionais Transitórias, para assegurar os recursos mínimos para o financiamento das ações e serviços públicos de saúde. Diário Oficial da União. 14 Set 2000.

31. Estado de São Paulo. Comissão Intergestores Bipartite. Deliberação CIB no 153/2007. A Comissão Intergestores Bipartite - SP, reunida em 19 de julho de 2007 referendou o reconhecimento de 64 Regiões de Saúde com respectivos colegiados regionais e os $17 \mathrm{DRS}$, enquanto macro-regiões com respectivas Comissões Intergestoras de abrangência macro-regional, conforme disposto no Anexo 1. Diário Oficial do Estado de São Paulo. 21 Set 2007.

32. São Paulo (estado). Comissão Intergestores Bipartite. Deliberação CIB no 4/2012. Considerando, a 50a Reunião ordinária do Colegiado de Gestão Regional de Saúde do Alto Tietê, realizada em 06/12/2011, que aprovou a fusão da Região de Saúde do Alto Tietê e da Região de Saúde de Guarulhos. Diário Oficial do Estado de São Paulo. 27 Jan 2012.

33. São Paulo (estado). Secretaria da Fazenda e Planejamento. Sistema de Informações Gerenciais da Execução Orçamentária (Sigeo). [internet]. [acesso em 2018 set 27]. Disponível em: https://www.fazenda.sp.gov.br/SigeoLeil31/Paginas/FlexConsDespesa.aspx.

34. European Commission. Health and Economic Analysis for an Evaluation of the Public Private Partnership in Health Care Delivery across EU. Bruxelas: European Union; 2013.

35. Barbosa NB, Elias PEM. As organizações sociais de saúde como forma de gestão público/privado. Ciênc. Saúde Colet. 2010; 15(5):2483-2495.

36. São Paulo (estado). Secretaria da Saúde. Portal Financeiro do Gestor. [internet]. [acesso em 2019 abr 2]. Disponível em: http://www.portalfinanceirodogestor.saude.sp.gov.br/.

Recebido em 11/02/2020

Aprovado em 22/08/2020

Conflito de interesses: inexistente

Suporte financeiro: não houve 